\title{
Obstructive Urethrolithiasis in a Mule
}

\author{
Rita de Cássia Campebell ${ }_{\odot}{ }^{1}$, Fernanda Barbosa da Silva ${ }_{\odot}^{2}$, Jorge Filipe Brito Silva ${ }^{2}$, \\ Letiana da Silva Rehbein ${ }^{1}$, Verônica Lourença de Souza Argenta ${ }_{\odot}{ }^{1}$, Elissa Ribeiro ${ }_{\odot}{ }^{1}$, \\ Gustavo Peixoto Braga ${ }^{2}$, Laís Velloso Garcia ${ }_{\odot}^{1}$ \& Antônio Carlos Lopes Câmara ${ }^{1}$
}

\begin{abstract}
Background: Obstructive urolithiasis is a rare but potentially serious condition in equids. In the reviewed literature, there are several case reports of urolithiasis in horses and donkeys, but the only mention of this condition in mules occurred as incidental findings at a slaughterhouse. Therefore, this work aims to describe the first report and successful treatment of obstructive urethrolithiasis in a mule (Equus asinus $x$ Equus caballus).

Case: A 10-year-old castrated male mule weighing $380 \mathrm{~kg}$ was referred for hospital care. Tachycardia (64 beats per min), mild dehydration (7\%), increased capillary filling time $(3 \mathrm{~s})$, slightly congested mucous membranes, and dysuria were observed. During its attempts to urinate, the mule was able to expose the penis, resulting in only dribbling of urine with reddish coloration. Urethral catheterization failed to reach the urinary bladder and revealed an obstruction at the ischial $\operatorname{arch}(7 \mathrm{x} 4 \mathrm{~cm})$, as confirmed by palpation and ultrasonography. Additionally, rectal ultrasound examination showed urine sedimentation and a single $2.36 \mathrm{~mm}$ vesical calculus. After sedation, local anesthesia, and surgical preparation, urethrotomy in the standing position was performed over the urethral obstruction at the ischial arch, reaching the urethrolith that fragmented during removal. Urethral catheterization from the urethrotomy site to flush the urinary bladder and urethra were performed, but the remaining vesical calculus was not retrieved. Considering the presence of a vesical calculus, severe urethral damage caused by the spiculated calculus and catheterization attempts, permanent perineal urethrostomy was performed. Laboratory tests revealed unremarkable hematological parameters, while serum biochemistry showed increased creatinine level. Urinalysis revealed cloudiness, amber appearance, countless red blood cells and bacteria, and calcium carbonate crystals. The urethrolith composition included ammonia, carbonate, and oxalate. Twelve months after surgery, the mule was healthy, the urethrostomy was viable, and no complications were recorded during this period.

Discussion: Although uncommon, there are reports describing calculi of different sizes and weighing up to $803 \mathrm{~g}$, causing mild to severe clinical signs according to the degree of obstruction in horses and donkeys. In the mule described here, the urethrolith did not completely obstruct the urethra, but the spiculated calculus caused dysuria and hematuria. In fact, most animals are usually referred for acute abdominal signs or hematuria and pollakiuria, but other unusual signs, such as rectal prolapse, may also be present. In the present report, the diagnosis of obstructive urethrolithiasis was established based on clinical signs and transcutaneous ultrasound of the subischial area, allowing visualization of the urethrolith. To the best of our knowledge, this is the first report of obstructive urethrolithiasis affecting a mule in Brazil. We reiterate that this condition must be included in the differential diagnosis of mules and hinnies with hematuria and dysuria, especially when associated with abdominal pain. Additionally, urethrostomy associated with urethrotomy performed on this mule in the standing position was a low-cost procedure with good results. Due to the lack of specificity regarding the food management of the mule on the previous farm, an assessment cannot be made regarding the effects of its food on urolith composition.
\end{abstract}

Keywords: Equus asinus x Equus caballus, urethrotomy, urethrostomy, urethrolith. 


\section{INTRODUCTION}

Obstructive urolithiasis is a rare but potentially serious condition in equids. In horses, approximately $84 \%$ of urolithiasis develop in the urinary bladder, where $60 \%$ remain in this location, and $24 \%$ pass to the urethra, causing urethral obstruction [5]. Urethral calculi usually result from small bladder stones that have moved to the urethra and are commonly lodged at the ischial arch, where the urethra narrows and changes its direction [3].

The pathophysiology of calculi formation in horses is poorly elucidated, but the mechanism behind their formation is believed to be directly linked to increased urine concentration, prolonged urinary retention time, and crystal growth promoters, such as inflammation and nutritional factors [5,6]. Squamous epithelial cells, leukocytes, non-absorbable sutures, and necrotic tissues have been reported as nuclei of cystic calculi, with high salt levels (mainly calcium carbonate), and urine alkalinity as predisposing factors [11]. Such characteristics can lead to solute precipitation, serving as the nucleus for mucoprotein consolidation and calculi formation [3,6].

In the reviewed literature, there are several case reports of urolithiasis in horses $[3,5,6,11]$ and donkeys $[1,10,14,15]$, but the only mention of this condition in mules occurred as incidental findings at a slaughterhouse [4]. Therefore, this work aims to describe the first report and successful treatment of obstructive urethrolithiasis in a mule (Equus asinus $x$ Equus caballus).

\section{CASE}

According to the owner, the mule was purchased for horseback riding, and since its arrival on the farm, after a long ride, the animal presented reddish urine and discrete discomfort. A practitioner attended the mule and suspected rhabdomyolysis, which was ruled out after biochemical tests. The owner opted to maintain the mule on the farm to free-range in the paddocks, mostly consisting of Brachiaria and Andropogon grasses. Eight months later, the mule was found in a stretched position, apparently with difficulty urinating. The mule was referred to the Large Animal Veterinary Teaching Hospital, Universidade de Brasilia, after $30 \mathrm{~h}$ of clinical evolution.

Upon physical examination, the 10-year-old castrated male mule was apparently calm, presenting a moderate body condition score (scale 3 out of 5 ) and weighted $380 \mathrm{~kg}$ on a digital scale. Tachycardia (64 beats per min), mild dehydration (7\%), increased capillary filling time (3 s), slightly congested mucous membranes, and dysuria were observed. During its attempts to urinate, the mule was able to expose the penis, resulting in only dribbling of urine with reddish coloration. All intestinal quadrants were hypomotile, and rectal palpation revealed small fecal pellets containing mucus and a severely distended urinary bladder. Urethral catheterization attempts failed to reach the urinary bladder and revealed obstruction at the ischial arch. Abdominocentesis was unproductive. Upon rectal ultrasound examination with a $7 \mathrm{MHz}$ probe ${ }^{1}$, sedimentation, and the presence of a single $2.36 \mathrm{~mm}$ vesical calculus were observed. Palpation of the penile tract revealed a hard mass in the penile urethra at the level of the ischial arch and a dilated urethra proximal to the mass (Figure 1A), which was subsequently confirmed and measured $(7 \times 4 \mathrm{~cm})$ using a $6-13 \mathrm{MHz}$ linear probe ${ }^{1}$.

Sedation was obtained using a continuous infusion rate of detomidine ${ }^{2}(0.01 \mathrm{mg} / \mathrm{kg})$ and butorphanol $^{3}(0.02 \mathrm{mg} / \mathrm{kg})$. Local anesthesia included epidural anesthesia with bupivacaine ${ }^{4}(0.06 \mathrm{mg} / \mathrm{kg})$, and local blockade of the pudendal nerve with $10 \mathrm{~mL}$ of $2 \%$ lidocaine without vasoconstrictor ${ }^{5}$ and $10 \mathrm{~mL}$ of bupivacaine ${ }^{4}$. Flunixin meglumine ${ }^{6}(1.1 \mathrm{mg} / \mathrm{kg})$, ceftiofur $^{7}(4.4 \mathrm{mg} / \mathrm{kg})$, and 5,000 IU of antitetanic serum $^{8}$ were administered preoperatively.

Under sterile conditions, a $6 \mathrm{~cm}$ midline skin incision was made over the urethral obstruction at the ischial arch. Then, the incision was continued through the bulbourethral muscle, corpus spongiosum, and urethral mucosa (Figure 1B), reaching the urethrolith that fragmented during removal (Figure 1C). A sample of the retained urine was collected for further urinalysis, along with the fragmented calculus for chemical analysis. Urethral catheterization was performed from the urethrotomy access point to ensure patency, and the urinary bladder and urethra were flushed using warm normal saline solution. Unfortunately, the 2.36 $\mathrm{mm}$ vesical calculus was not retrieved during flushing. Therefore, considering the presence of a large vesical calculus and severe urethral damage caused by the spiculated urethrolith and catheterization attempts, permanent perineal urethrostomy (Figure 1D) was performed as previously described [2]. Postoperatively, 
urethral catheterization was maintained for $48 \mathrm{~h}$. Drug therapy consisted of flunixin meglumine ${ }^{6}[1.1 \mathrm{mg} / \mathrm{kg}$, IV, q24h, 3 days] and ceftiofur ${ }^{7}[4.4 \mathrm{mg} / \mathrm{kg}, \mathrm{IV}, \mathrm{q} 24 \mathrm{~h}, 7$ days]. Both surgical wounds were dressed twice daily with diluted (1:100) iodopovidone solution, followed by healing ointment until complete healing which occurred on day 15 after surgery (Figure 1E).

Laboratory tests performed on the first day post-surgery identified no changes in hematological parameters, while serum biochemistry revealed increased creatinine ( $2 \mathrm{mg} / \mathrm{dL}$ reference values: $0.88-1.2$ $\mathrm{mg} / \mathrm{dL}$ ) level, and discrete hypoalbuminemia (2.4 g/ $\mathrm{dL}$; reference values: 2.6-3.7 mg/dL) [13]. The maintenance rate of lactated Ringer's solution therapy was administered for 3 consecutive days until creatinine returned to the reference values for mules $(1.1 \mathrm{mg} / \mathrm{dL})$. Urinalysis revealed abnormalities in physical (amber color, fetid odor, and cloudy aspect) and chemical evaluation (proteinuria and occult blood). Examination of urinary sediments revealed countless red blood cells and bacteria, rare leucocytes, and calcium carbonate crystals. Macroscopically, the fragmented urethrolith showed a spiculated and irregular surface, dark coloration, and stony consistency, while chemical analysis revealed a composition of carbonate, ammonia, oxalate, and calcium (Table 1). Twelve months after surgery, the mule was healthy, the urethrostomy was viable, and no complications were recorded during this period (Figure 1F).

\section{DISCUSSION}

Calculi in horses are most commonly found in the bladder, while urethral, renal, or ureteral calculi are less common [9]. Relatively large urethral uroliths that cause obstruction in horses are rare [5]. However, there are reports describing calculi of different sizes [2,12] and weighing up to $803 \mathrm{~g}$ [8], causing mild to severe clinical signs according to the degree of obstruction in horses [3,6,11], and donkeys [14,15]. Uroliths obstructing the urethra of male horses may be related to urethral narrowing at the ischial arch [5]. In the mule described here, the urethrolith did not completely

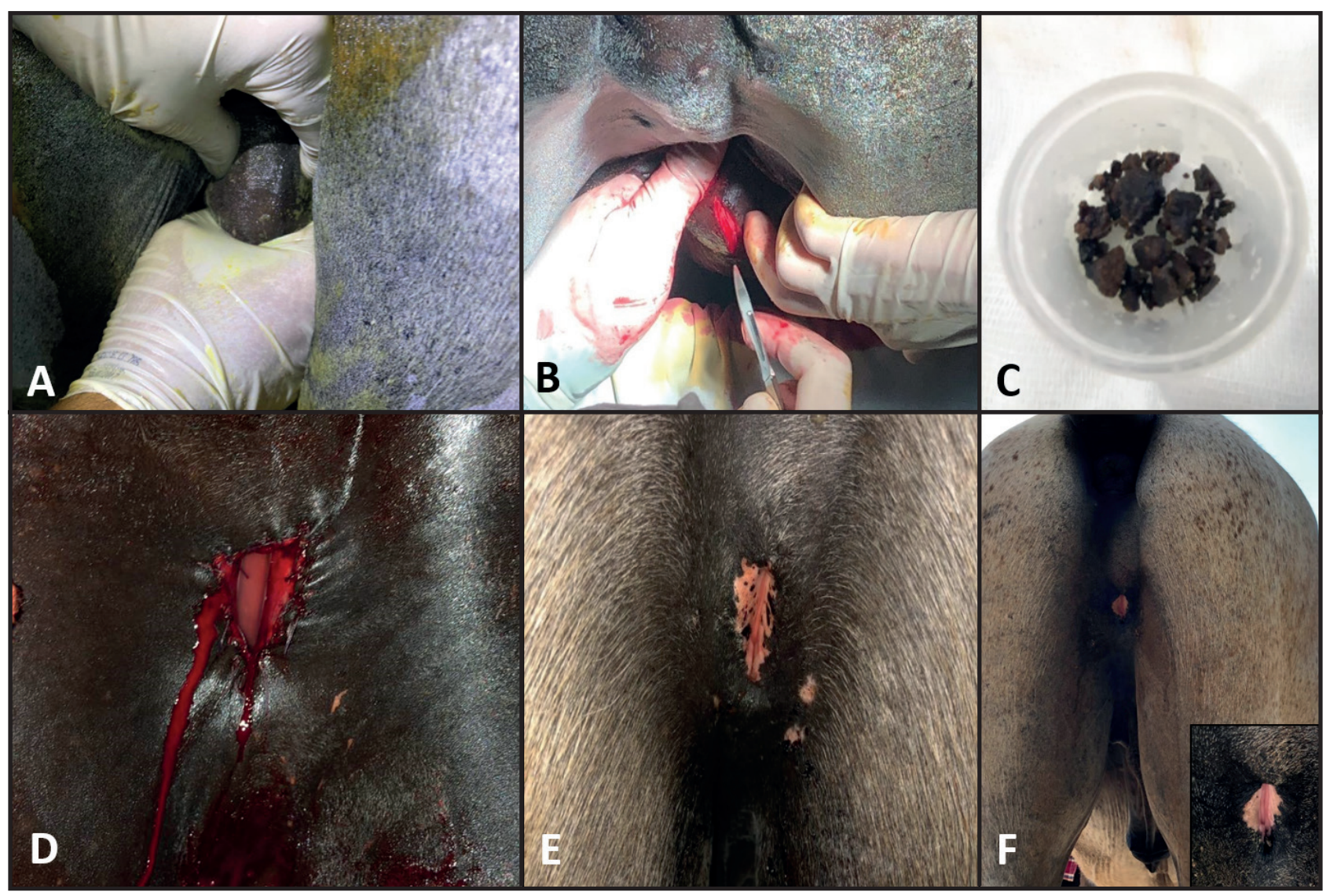

Figure 1. Obstructive urethrolithiasis in a mule. A- Palpation and urethrotomy location at the ischial arch. B- Urethrotomy at the site of a urethral calculus $(7 \mathrm{x} 4 \mathrm{~cm})$. C- Fragmented urethral calculus after removal. D- Permanent urethrostomy aspect immediately after surgery (inverted triangle incision of $10 \mathrm{~cm}, 10 \mathrm{~cm}$ away from the anus). E- Permanent urethrostomy aspect 15 days after surgery presenting complete healing. F- After 12 months of the surgery: the permanent urethrostomy remains patiency [Inset: closer view]. 
Table 1. Results of urinalysis and urolith analysis from a mule with obstructive urethrolithiasis.

\begin{tabular}{|c|c|c|c|}
\hline \multicolumn{4}{|c|}{ Urinalysis } \\
\hline Color & Amber & Protein & $100 \mathrm{mg} / \mathrm{dL}$ \\
\hline Odor & Fetid & Red Blood Cells & countless \\
\hline Turbidity & Cloudy & Bacteria & countless \\
\hline Specific gravity & 1.040 & Leucocytes & Rare \\
\hline $\mathrm{pH}$ & 8.0 & Crystals & Calcium carbonate \\
\hline Occult blood & +++ & & \\
\hline \multicolumn{4}{|c|}{ Urolith analysis } \\
\hline \multicolumn{2}{|c|}{ Physical } & \multicolumn{2}{|c|}{ Chemical } \\
\hline Weight & $4.63 \mathrm{~g}$ & Carbonate & +++ \\
\hline Form & Spiculated & Oxalate & ++ \\
\hline Color & Blackish & Calcium & + \\
\hline Consistency & Stony & Ammonia & +++ \\
\hline
\end{tabular}

obstruct the urethra, but the spiculated calculus caused dysuria and hematuria. In fact, most animals are usually referred for acute abdominal signs [3] or hematuria and pollakiuria $[8,14]$, but other unusual signs, such as rectal prolapse, may also be present [15]. Hematuria usually occurs as a consequence of the urolith affecting the urinary bladder mucosa causing irritation and bleeding, and is exacerbated by exercise [3], which was also referred to in the mule's history. This is similar to previous clinical manifestations described in a donkey with hematuria and intermittent colic episodes, until the spontaneous expulsion of the calculus [1]. Additionally, a donkey with complete obstruction demonstrated hematuria, dysuria, strangury, tenesmus, painful urination, and penile protrusion [10].

In the present study, the diagnosis of obstructive urethrolithiasis was established based on clinical signs and transcutaneous ultrasound of the subischial area, allowing visualization of the urethrolith, as described previously $[3,6]$. In large animal practice, ultrasonography is a helpful diagnostic tool for the detection of the number, size, surface, and location of the urinary stones [3]. Cystoscopy may also be an important ancillary tool for diagnosing vesical uroliths [14].
When the obstruction is located more distally within the perineal urethra, the incision is indicated directly on the calculus, ventral to the ischium tuberosity [7], as performed in this study. Additionally, standing urethrotomy was performed due to the urethrolith's easy access and surgical facilities, in addition to being a non-invasive and low-cost procedure $[2,3,6]$. Approximately $41 \%$ of horses treated for urolithiasis showed recurrence between one and 32 months after surgical treatment, particularly after subischial urethrotomy [9], which may be a consequence of vesical calculi debris and chronic cystitis [12]. Another reported late complication was stricture at the urethrotomy site in two miniature donkeys [7]. Urethral narrowing may occur from damage to the urethral mucosa and urolith manipulation, leading to postoperative inflammation and fibrous tissue formation at the surgical site. In addition, large uroliths removed by urethrotomy often have a spiculated surface and cause trauma to the urethral mucosa during manipulation and extraction, favoring urethral narrowing [12]. This was associated with the presence of a $2.6 \mathrm{~mm}$ vesical calculus in this mule and was a crucial reason for the permanent perineal urethrostomy choice. In previous reports of urethrostomy, prior urethral catheterization through the urethrotomy 
access helped prevent midline incision deviation and cranial urethral wall penetration [7]. Nevertheless, chemical burns or rashes formed due to urine running down the animal's legs is also a reported complication associated with extension of the perineal urethrotomy incision ventral to the ischium [7]. Fortunately, in our case, this complication was not observed 12 months after surgery, and the mule adapted to urinate through this new access.

In this report, the appearance of the urethrolith was similar to that of calcium carbonate spiculated calculus [6]. However, chemical analysis revealed a greater amount of carbonate, ammonia, and oxalate. Similar findings were observed in a 10-year-old female donkey [1] and an 8-year-old mare [8] that spontaneously expelled a large calcium oxalate and calcium carbonate calculus, respectively. Additionally, a large amount of grain and brackish water intake might have caused excess calcium intake, favoring urethral calculus formation in a donkey in Sudan [10]. It is believed that the high prevalence of calcium carbonate is due to its natural presence in the equid's urine, and that excessive calcium excretion leads to urolith formation. This may also be associated with crystallization inhibitor deficiencies and urine $\mathrm{pH}$ changes [9]. Predisposing factors for crystal precipitation include increased urine concentration, prolonged urinary retention time, and crystal growth promoters such as inflammation and nutritional factors [5]. Unfortunately, in this case, it was not possible to assess the cause of the urethrolith formation. No recurrence was observed, and urethrostomy remained viable one year after the surgical procedure, proving the technique adequacy with a satisfactory outcome that pleased the owner.

To the best of our knowledge, this is the first report of obstructive urethrolithiasis affecting a mule in Brazil. We reiterate that this condition must be included in the differential diagnosis of mules and hinnies with hematuria and dysuria, especially when associated with abdominal pain. Additionally, urethrostomy associated with urethrotomy performed on this mule in the standing position was a low-cost procedure with good results. Due to the lack of specificity regarding the food management of the mule on the previous farm, an assessment cannot be made regarding the effects of its food on urolith composition.

\section{MANUFACTURERS}

\author{
${ }^{1}$ Sonosite Inc. Washington D.C, USA. \\ ${ }^{2}$ Ouro Fino Saúde Animal Ltda. Cravinhos, SP, Brazil. \\ ${ }^{3}$ Zoetis Indústria de Produtos Veterinários Ltda. Campinas, SP, \\ Brazil. \\ ${ }^{4}$ Hipolabor Pharmaceuticals Ltda. Belo Horizonte, MG, Brazil. \\ ${ }^{5}$ Hypofarma Instituto de Hypodermia e Farmácia Ltda. Ribeirão das \\ Neves, MG, Brazil. \\ ${ }^{6}$ Ceva Saúde Animal Ltda. Paulínia, SP, Brazil. \\ ${ }^{7}$ Eurofarma Laboratórios S.A. Ribeirão Preto, SP, Brazil. \\ ${ }^{8}$ Laboratórios Vencofarma do Brasil Ltda. Londrina, PR, Brazil.
}

Declaration of interest. The authors report no conflicts of interest. The authors alone are responsible for the content and writing of the paper.

\section{REFERENCES}

1 Abdel-Hady A.A.A. 2014. Spontaneous repelling of a large urocystolith in a working she-donkey. Scholars Journal of Agriculture and Veterinary Science. 1(3): 105-106.

2 Adams A. \& Hendrickson D.A. 2014. Standing male equine urogenital surgery. Veterinary Clinics of North America: Equine Practice. 30(1): 169-190.

3 Abu-Seida A.M. \& Shamaa A.A. 2020. Ultrasonography and surgical treatment of an unusual case of urethral calculus in an Arabian horse. Journal of Equine Veterinary Science. 92: 103150. doi: 10.1016/j.jevs.2020.103150.

4 Diaz-Espiñeria M., Escolar E., Bellanato J. \& Rodriguez M. 1995. Structure and composition of equine uroliths. Journal of Equine Veterinary Science. 15(1): 27-34.

5 Edwards B. \& Archer D. 2011. Diagnosis and treatment of urolithiasis in horses. In Practice: 33(1): 2-10.

6 Ferreira M.A., Brito P.H.S, Prado Filho R.R., Arantes J.A., Godoi G.S., André G.A.S., Mizobe T.S.P. \& Dória R.G.S. 2019. Obstructive urolithiasis in horse. Acta Scientiae Veterinariae. 47: 436. 5p.

7 Kilcoyne I. \& Dechant J.E. 2014. Complications associated with perineal urethrotomy in 27 equids. Veterinary Surgery. 43(6): 691-696.

8 Kozdrowski R., Henklewski R., Dzieciol M. \& Bednarski M. 2010. A large urolith in an 8-year-old mare: a case report. Veterinarni Medicina. 55(6): 285-288.

9 Laverty S., Pascoe J.R., Ling G.V., Lavoie J.P. \& Ruby A.L. 1992. Urolithiasis in 68 horses. Veterinary Surgery. 21(1): 56-62. 
10 Lazim S.A.M., Elrahman K.A. \& Mohammed M.Y. 2017. First report of urolithiasis in a donkey in Western Kordufan, Sudan. Journal of Traditional Medicine \& Clinical Naturopathy. 6(1): 1-2.

11 Macêdo J.T.S.A., Biscarde C.E.A., Nascimento K.A., Ferreira Júnior J.A. \& Pedroso P.M.O. 2017. Obstructive urethrolithiasis in a horse. Acta Scientiae Veterinariae. 45(3): 238. 3p.

12 Mair T.S. \& Holt P.E. 1994. The aetiology and treatment of equine urolithiasis. Equine Veterinary Education. 6(4): 189-192.

13 McLean A.K., Wang W., Navas-Gonzalez F.J. \& Rodrigues J.B. 2016. Reference intervals for hematological and blood biochemistry reference values in healthy mules and hinnies. Comparative Clinical Pathology. 25(4): 871-878.

14 Mendoza F.J., Toribio R.E. \& Perez-Ecija A. 2018. Donkey internal medicine - Part II: Cardiovascular, respiratory, neurologic, urinary, ophthalmic, dermatology, and musculoskeletal disorders. Journal of Equine Veterinary Science. 65: 86-97.

15 Robert M.P., Boissiere A.M., Depecker M.C., Fourmestraux C., Touzot-Jourde G. \& Tessier C. 2016. Type IV rectal prolapse secondary to a long-standing urinary bladder lithiasis in a donkey. Equine Veterinary Education. 28(11): 625-630. 